\title{
Marxism Modernization and Sinicization
}

\author{
Su Wuxun \\ (Professor of National Hua qiao University, Quanzhou, Fujian, China 362021) \\ E-mail: suwuxun6789@vip.163.com, suwuxun@hqu.edu.cn
}

\begin{abstract}
Keywords: Marxism Modernization and Sinicization, Three aspects of Marxism Modernization, Marxism Sinicization in current China, New basic economy system and political system
\end{abstract}

\begin{abstract}
This article is the outline of my book "Marxism Modernization and Sinicization" as the document for consultation and cooperative purpose. In the book three aspects of the Marxism modernization are point out: 1, the development of human society has changed from the spontaneous development into the consciousness development; 2, the development law of human society has been according to the consciousness developing law after War II---what is the consciousness developing law; 3, the Marxism philosophy study has to enter another field - the general law of mutual interactions of same kind objects at different development stages. Then in the book there also discuss the question of Marxism sinicization, especially on the current situation of China; Review on the current Chinese economic and political system; the implementation of basic economic system reform (the three third shareholding system) and the establishment of corresponding political and legal system; from bottom to top development planning proposal of social economy; confirmation and authorization of the economic development plan in different regions and the whole nation; the implement of plan by different region regime and government executive agencies; promoting the society informatization various kind productive forces informatization and corresponding socialization and consciously establish related socialized productive relations to promote the productive forces be transformed into socialized linked ones and be brought into the total social precise supervision systems and conscious developing orbit; The role of the consciousness developing of China to the world;
\end{abstract}

\section{Preface}

Entering into 2017, along with the new president Trump of the United states appears on the stage and the $19^{\text {th }}$ National Congress of the Communist Party of China (CPC) will be about to be held later, the world and the China all are faced with the new opportunities and challenges. How aright grasp the development directions of the world and China is the problem the people is urgent to be solved. Correct understanding the world and China need correct thought guidance. The development history of Marxism has proved that the understanding of it to the history development of human society is quite correct. Faced with current problems of the world and China, Marxism has to be modernized and sinicized.

Marxism Modernization and Sinicization are two different issues, but they are closely related. Marxism Modernization is refers to develop the Marxism to adapt the evolution of current human society, meanwhile Marxism sinicization is refers to combine the modern Marxism with the current Chinese society practice in order to direct the current society development of China.

\section{Marxism Modernization}

Living in the society the capitalism was flourishing, the founder of the Marxism-Karl Marx set forth the spontaneous development law of human society in the famous 《Preface of animadvert on the political economics》 in $1859^{[1]}$ and set up the Dialectical historical materialism and pointed out that the spontaneous development of human society is end up by the capitalist society. Lenin inherited the Marxism and pointed out that the highest stage of the development of the capitalist society is the monopoly capitalism---imperialism. But the imperialism is just the warfare. The twice of the World War-the first and second world war have proved the correctness of the Lenin's 
prediction. Lenin also pointed out that only need one step from the state capitalism forward, that is, after changing the system of ownership from the private to the public ownership, the society is becoming the socialism. However after the Lenin passed away, the hegemony of the Communist Party of the Soviet Union (CPSU) had fallen into the hands of Stalin. His thought on the social system and the insistence of Marxism was retrogress of the Lenin's period. Although the Stalin leaded the Soviet Union people defeating the Germany Fascism and winning the Second World War; but for the task of modernizing the Marxism, Stalin and the CPSU wasn't able finish it at all. The history has proven that conclusion and hence the CPSU was becoming feeble and die.

Why the spontaneous development of human society is end up by the capitalism society? From the point of view of the development of the productive force, the spontaneous development of human society before the capitalist society was based on spontaneous development of productive force, which was the small production. Hence the development of that productive force was spontaneous, by accident and un-expectant. It is just this sort nature of productive force's spontaneous development to promote the spontaneous develop of the human society.

However the socialized great productive forces based on the modern science and technology was the foundation base of the capitalist society. Socialized great productive forces must be established on the modern sciences (including natural science and social science) and technologies (hence the discovers, creations, inventions and innovations all are the first elements of the development of the socialized great productive forces) and needed to be coordinated and cooperated in the whole social range then the socialized great productive forces can be formed and developed. In other words, only have the elaborate social organization and coordination and a variety of social resources are to be carefully configured and harmoniously cooperated, the modernized great productive forces can be formed and developed. So the socialized great productive forces can't develop spontaneously, it must develop consciously. For this reason entering into the capitalist society, the inherent nature---the socialized great productive forces must develop consciously-require the human society must consciously carve out the developing way for them. So the development of the human society after the wide emerge of the great socialized productive force can't develop spontaneously like before: under the driving of the productive forces, superstructure and ideology would be changed spontaneously or early or later to adapt the need of the development of human society in a passive manner.

In order to adapt the inherent nature of the great socialized productive force---must develop consciously, human society has to follow the consciously development law of it: the social force grasping the hegemony of the society must select consciously the variety and types of the great socialized productive force, which are adaptable to the current development levels of the society and consciously utilize the whole power of the superstructure and ideology, invoke various social sources (capital, manpower, land and so on), change the existing social relation and conditions and create various kinds of necessary conditions to carve out the development ways for them; meanwhile in this process the consciously development of the society in all aspects are promoted largely forward. That is to replace the spontaneously development by the consciously development of human society. That is the most important one of the core content of the Marxism modernization: carry forward the cognition to the development of human society from the spontaneous development law into the conscious development law.

Must develop consciously ---the inherent nature of the great socialized productive force is entirely incompatible with the occupying of it by the capital. The operation of the great socialized productive force needs the consciously coordination of the capital (equipment, plant, various hardware facilities and so on), intellectual property and manpower resource team. Ignoring the pivotal role of the manpower resource team in realizing the great socialized productive force and the value transfer and letting the capital monopolize all the profits will inevitably hit the enthusiasm, consciousness and creativity of the manpower resource team and inevitably hinder the consciously development of the great socialized productive force. Meanwhile the vast people will not be able to get their reward corresponding to their labor (their salary got only the reproduction cost of the manpower, in some cases employer even does the reduction of wage, the gain of the laborer only is 
the basic life maintenance fee.) That not only causes the big differences between the rich and the poor and the polarization of the society, but also the lower of the consumption level of the vast labor group which make the lower level of whole consumption of the society. Hence the consumption of the society can't become the strongest driving power of the production of the society but on the contrary become the essence source of the cyclical crisis of relative surplus in capitalist society.

Therefore the inherent nature of the great socialized productive force---must develop consciously require the whole society must consciously configure various social resource, carve out the development road for the productive force and make the variety of the social relations (from the economic foundation to the superstructure) be the promoting forms of the great socialized productive force. That is the origin of the historical inevitability of the capitalism will inevitably be replaced by the socialism, which can configure all social resources consciously and can change and create various new types of relations.

Hence there is another important aspect of Marxism modernization. That is the research on the basic social structure and operation law that human society can realize the consciously developing. On that issue author regard as that: the society that can realize the consciously developing must have some basic conditions as follows:

Human society has developed into the post-modern civilization in 21 century. SO at first there must be certain liberty and democratic social surroundings to make all the members of the society could freely express their thought and political、social aspirations and through the mechanism the society identify elect the social force to the station of the society leadership and form the conscious social leadership force, by which the society conscious developing only could be realized.

Secondly the society should firstly establish one national economy macro-administrative department, which started from the current practical situation of own country (or own region) and consciously choose the various sorts and corresponding technology levels of socialized great productive forces adaptable for it and estimate the possible industry scale and make the medium and long term industry plan for them which as the base of the consciously development of society. To realize this task it is necessary through the above conscious choosing and concentrating the conscious consensus of the whole society and their carrier---corresponding experts and talents to constitute the conscious society leadership force, just under the leadership of which the society is possible to develop consciously forward.

Once more it is essential to establish the proper economic system and corresponding superstructure adaptable to the conscious developing of the great socialized productive forces, from the enterprise basic economic system to the economic administration system on whole society and their corresponding legalization---guarantee the establishment of the socialism economic system and it's consciously operation by legal form. That part content would be discussed in the sections related to the Chinese open and reform because in current world only in the China there could be possible to establish that economic system.

Once again conscious developing society has to actively reform the various social resources the developed capitalist society has been creating yet to adapt the society conscious development requirements. For example reform the capitalist market economy into the socialist market economy with conscious macro control and precision market supervision, because only the market economy can satisfy the variety necessary demands of the social people. Meanwhile reform the capitalist investment market of all kinds of production elements into the investment market with conscious supervision and size control and so on.

Finally in the ideology fields, with the fully liberty and democracy having established, the enthusiasm, consciousness, creativity of entire people have to be fully stimulated not only for the conscious developing of human society but also for the conscious evolution of the species of human beings itself.

Another important aspect of Marxism modernization is to carry through thorough research in the Marxism philosophy field. The three laws of materialistic dialectics, law of the unity of opposites, object evolves from quantitative change to qualitative change and negation of negation, are fully set forth in Engles's Anti-Duhring and Lenin's works. Those laws are the universal law of 
object evolution. The issue in Marxism philosophy has to perform a thorough study is the universal law of the interactions among the objects of the same kind but at different development stages to direct the human beings' interactions with society and natural world.

Through the analysis and summarization to the human societies development since modern times, author thought that: among the same kind objects at different stages - at advanced middle and lower stage, the objects at middle stage are at the stage, in which the contradictions are at the most centralized and complicated status. Because at that stage except the contradictions of itself, there are advanced stage's guidance and lower stage's encumber and delaying to it, that makes the struggles among various forces most centralized and intense and promotes the objects at middle stage developed more quickly and transcend the object at advanced stage and enter the another higher developing phase. So the comprehensive development of objects at different stages appears an interdigitate and spirals situation. However the object entering the higher developing phase with its original centralized and complicated contradictions perhaps because of the actions of the original advanced forces can still along the path of the higher developing phase develop; meanwhile it also perhaps because of the actions of the original strong lower forces will retrogress back to low grade stage in another status.

The Russia in the before-and-after of the First World War is one of the examples of object at middle stage. Under the leadership of Lenin she realized the leap-type development; however the Soviet Union after Lenin, under the leadership of Stalin she did not continue the leap-type development and finally retrogress back to the lower development phase in some kind of forms.

The China in the before-and-after of the Second World War is another example of object at middle stage. Under the leadership of Communist Party of China (CPC) the China realized the leap-type development. After the establishment of the People's Republic of China the CPC also gropingly with difficulty seeks the correct developing road to the higher development phase in a status with vacillating to the left and right. After going through the Mao Zedong era and the more than 30 years of Open and Reform, under the leadership of Xi Jinping China is moving towards the relatively correct developing directions but faced the heavy tasks: correct the history mistakes in the previous two periods of history and eliminate their serious social consequences (like the dualization of the society, polarization of poor and rich, serious destruction of the ecological environment and corruption by the stratum and so on). At present austere international and historical environment whether the China can realize the development at higher level---the conscious developing at the present highest level of human society yet or not is a serious problem. To make that problem be solved and realize the conscious development of China it is necessary to concentrate the whole national wisdom and consciousness of the Chinese nation and all to be started from the point -the supreme interests of the people and Nation. Only by that the China can finish the transformation from the spontaneous developing into the conscious developing and lead the whole human beings enter the new developing era: not only consciously in society developing but also in biological species evolution.

\section{Marxism sinicization}

Marxism sinicization began in the May $4^{\text {th }}$ Movement in 1919 . As the sound of a bomb went the air in the October Revolution the Marxism was sent to the China is an accurate judgment. The establishment of CPC makes the Marxism sinicization having a historical carrier. However because of the long term social history environment of China, the Marxism sinicization has gone through and been going through a difficult history progress. In the new democratic revolution stage CPC was going through the right-and left swing and finally found and selected the correct revolution roadway in the colony, semi-colony and semi-feudal social history environment of China which surround the cities from the countryside and oppose the armed counter-revolution forces by the armed revolution ones. There should be correct understanding and analysis to china society at that time; should be correct analysis to main social contradictions and historical functions of various social forces of china society at that time. In fact peasant uprising in successive dynasties in China 
has included abundant ideology and practice resources of despoiling the nationwide regime. Therefore that road was put forward by the Mao Zedong is absolutely not an accident matter because he was the man being the most familiar with the countryside situations and Chinese history of feudal society within CPC.

But that only is the lowest phase of the Chinese development course transforming from the colony semi-colony and semi-feudal society into the conscious developing society adaptable to the socialized great productive forces. While obtaining the regime of whole country what the road should along of the developing of the China society the CPC was in a spontaneous and groping manner. Learning from the Soviet Union turned into an active but also a passive option. In fact the CPC is not completely realizing the actual social situations of Soviet Union under the rule of the Stalin. However learning to implement the planned economic system and going the industrialization road from the Soviet Union is rather successful and promotes the development of China at that time but at the expense that the peasants suffer the exploiting of price scissors meanwhile the workers' wages were lowered to the minimum of subsistence. Hence the national assets accumulated should belong to the whole people including whole peasants. However there still has no consciousness on the developing path of China within the CPC. "Do not worry few and little, but worry unevenness"; and even subsequent the Three Red Banners, tendency toward boasting and exaggeration, running into communism and so on are all being the typical manifestation of the petty bourgeoisie "left" infantilism; running to later even forbid the spontaneous small production by peasant in edges of fields, that is not allowing productions and obviously want to strangle the developing of productive forces; that result in the tension supply of food and ordinary life consumer goods in all the country; moreover faced the peasants, not saying it is the extorting excessive taxes and levies but is the levy duty overtaxed; there is no enough grain ration in peasant-self; peasants take the eggs , poultries and other agricultural products go to the towns to exchange the food coupons with residents are emerged in endlessly over the country. Until after the Open and Reform the peasants are fully allowed to develop own freedom production the China has just got rid of this dilemma. But at that time the criticizing to "the three self-owned and one by contract" and "four kinds of freedom", which are proposed by the Liu Shao-qi and Deng Xiao-ping, became one of the reason to carry out the Great Cultural Revolution. The progress of Chinese society entering the Great Cultural Revolution and ended from it must have special chapters to discuss; but that reflected the fact that there were insuperable contradictions and had no consciousness to how to develop the Chinese society within the CPC. That also is a manifestation of the long term history development inertia of Chinese society in the feudal society phase.

After passing away of Mao Zedong, the fall from power of the "Gang of Four" at least reflected the sober action of far-sighted personage inside the CPC. The put forward of the reform and opening policy is account for that the stratum being in power is aware of the importance of developing the productive forces. Then the successes of The Four Asia Tigers outside give them a great stimulation and prompt them make up their mind to make the Chinese productive forces be rapidly developed. That is--in Deng Xiaoping's words: A blood way must be cut out.

However how to develop the productive forces of Chinese society at that time is quite disputed. In fact according to the point view of Marxism consciously establish various kinds of productive relations adaptable to corresponding productive forces and invoke a variety of social resources to fully promote the procreative development is right valid. But at that time how to consciously establish various kinds of productive relations adaptable to corresponding productive forces and corresponding social system is an unknown matter to the CPC, even to whole China. So "crossing the river by feeling the stones", "need not argue and doing first then by say", "developing is the absolute principle" and so on are becoming fashion and "truth". The stratum in power is along with this trend, through several times of tides, taking vast of the national assets (of the whole people) into own pockets. That made the present interest groups and the minorities' stratum occupying enormous wealth, which has become huge resistances to the further conscious developing of Chinese society. Just in the vacillating to the left and right, even if developed the productive forces and achieved the second GDP in the world, China has paid out heavy price: corrupt stratum 
mastering the power, the country has been disintegrated by serious ecological environment pollution, severe polarization between the rich and poor and dualization of society and urban and rural; all of them are the encumber of keeping on the developing of China and the history hinder of Chinese society entering the consciously developing phase.

For the CPC, which was born in the colony, semi-colony and semi-feudal social history environment of China and the bases of which were the peasants; After being in power, which was implementing the confining policy in ideology, hitting the intellectuals and growing up in such a political and economic environment there were no sufficient freedom of the people in politics and expression; the CPC want to realize: eliminate the history bills due, regain the trust of the people and initiate the conscious developing of Chinese society in current complicated international and inland history environments indeed is a heavy history burden; But the Chinese history precisely has put the heavy burden on the shoulders of CPC. What the CPC can do is just abandon the own prerogative and private interests of the ruling party, avoiding the miserable end of breaking away from the people similar to the CPSU (Communist Party of the Soviet Union); take the fundamental interests of whole nation as the starting point and concentrate the spirit、wisdom and knowledge of the whole nation to realize the conscious developing of Chinese society in the world and guide the conscious development of post-modern societies of human beings and evolution of human species and realize the formation of the community of human destiny and its conscious developing and hence really realize the great revival of Chinese nation.

The Marxism sinicization at present is to combine closely the conscious developing law of human society with the social practice of current China to lead the conscious developing of Chinese society. Because of, not only, the vast territory and abundant resources and the big geography span in China, but also the China is a multinational country, the developing levels in different regions are, of course, uneven. So it is necessary to start from the different levels of the regions and implement the various development strategies economic and social development paths adaptable to each region or area in order to realize conscious developing of regions. That put forward an austere challenge to the centralization system of authority and the conscious leadership of the Central Committee of CPC and all or different levels. Moreover the fact in more than 30 years in the reform and opening: only the GDP 、 making a start on and getting down from like a swarm of bees、 undesirable expansion of various kinds of industries and capacities and so on, all illustrates the lowly levels of the leadership of the stratum in power; The reason is simple: the purpose of their wielding the power was not around the center of the peoples' benefit, but around the center of their private interests and relative stratum's benefits; they were corrupting in unprecedented vigor and breadth; for the private interests they can betray country and nation so that they would rather to be nailed on the history shameful pole but still want to continue insanely. The current achievements of China are largely due to the limited open to the privately operated economy and introducing the foreign capital. Of course there are a multitude of capable brains and honest patriots within the CPC. That makes the Chinese history not along the road forward wanted by those usurping the state power but gradually turns to the correct history pathway. At present there is a life-and-death struggle between the two routes in China. The people of whole country should exert all the energies to help the President Xi Jinping and the Central Committee of CPC to defeat various interest groups 、 corrupt officials and a variety of hostile forces at home and abroad and acquire further victory of reform and opening---realizing the consciously developing of Chinese socialism society.

At present, having been implementing the reform and opening more than 30 years, the reform is at the key assaulting fortified positions stage. The task is to build a new type of socialism, which could consciously configure various social resources and consciously change or create various new type of social relationship to promote the developing of Chinese society.

At first establish the unitive property rights system in categorizations of whole society to create the basic conditions for unified configuration of resources.

Secondly establish the macro-management and guidance mechanism for the development of great socialized productive forces: implement the conscious guidance and size control for the great socialized productive forces; for small productive forces applying the social informatization means 
make them regionalization and socialized so that they become the social linked productive force systems and being guided and the size is regulated; for various traditional artisan craftsmanship they should be supported to maintain the history quintessence.

Thirdly reform the essential economic system. Let the three basic elements of the great socialized productive forces---capital, intellectual property, manpower resource team---each occupy one third of the entirety share. The capital and intellectual property have to devote the found and the rights of the property to get the one third shares and corresponding rights and interests. The earnings of the capital should encourage the past resources actively put into the current productive practice. Meanwhile the earnings of the intellectual property should encourage the people continue to proceed the creative labor and have some discovery, some new creations and some inventions and innovations in science and technologies and opening up the new roads for productive forces. But for the manpower resource team, needn't invest fund, they have to occupy the one third of the entirety share because only through their active and conscious participation the creation of the new values and the transferring of the old values of the capital and the intellectual property into the new products can be realized. Also only in this way the manpower resource team could obtain the one third of the profits of the enterprise except the salaries (which are sufficient cost of the reproduction of manpower) as the reasonable reward of their functions in production process. That will greatly motivate the enthusiasm、 consciousness and creativity of the manpower resource team and promote the developing of the productive forces. In addition the enhancement of the income of the vast laboring people will also greatly increase the consumption levels of whole society and become the most powerful motivation of social economy development. Moreover the further development of social production should provide more incomes for the vast laboring stratum and hence further enhance the consumption levels and promote the social production developing into higher layers and levels. By that way the conscious developing of the entire society do form the benignant positive cycle and completely overcome the fundamental contradiction between capitalist society and the developing of great productive forces. By that way it is impossible for the relative surplus crisis to be occurred. At that time there are the vast laboring people have the sufficient power and levels of consumption. The consumption and the production are mutual promoted and do form the excellent positive cycle and completely overcome the inherent contradiction of the capitalist society.

There is a well-known company---Huawei Group in China. In which there is implemented the most advanced economic system in the world so that every member of the company all are working in a consciously creatively manner. Its success is obvious to all of world. That also is the basic direction of reform of Chinese enterprise.

Followed is to reform the essential political institution. On the overall background of modern information and communication technology and internet establish the social democracy system, which combine the direct and indirect democracy and can reflect the entire social conscious awareness to society developing. Through which the most conscious social forces can be elected to the society leadership station and under the supervision of the people they can carry out the authority and duty the people vested to promote the society conscious developing all around. The system such as should for every qualified voter establish unique ID and a unified political opinion expression system of the people organized in different regions and layers. According to certain encryption program each citizen registers and enters the expression system and expresses various kinds of political aspirations as requested. Then the system on the basis the law authorized operates the program automatically and no man-made interference and reports the results to the corresponding authority department. Afterwards the corresponding authority department takes the relevant actions. That just is the physical and legal basis of really socialism democracy political system.

Changing with each passing day of the social information internetwork not only links every one of the society but also can link all objects on earth through the Internet of Objects. All of that have provided the massy physical basis for the social democracy system and the political system, which could concentrate the consciousness of the whole society. The various kinds of great socialized 
productive forces and the modern information communication and switching technique all are to provide the massy material basis. The human beings should consciously apply these achievements of science and technology to promote the conscious developing of human beings and the evolution of human species.

\section{Summary}

Finally there must be the first in China and gradually expand to the world to establish the global common culture system, by which humankind is developing harmoniously with the natural environment and the consciousness of self-evolution is enhanced, and carve out the broad road for the conscious developing on the earth and exploiting the other vivo-sphere in universe.

The author e-mail and mobile phone: suwuxun6789@vip.163.com, suwuxun@hqu.edu.cn, 0086-13505995698.

\section{References}

[1] Karl.Marx, That preface in Chinese origins in p194-195 of vol.2 of 《The florilegium of Marx and Engels》published by the People Press in 1966 in China. The English edition of that preface is omitted here for short. 